Check for updates

Cite this: RSC Adv., 2018, 8, 7029

\title{
Sonochemical preparation of alumina-spheres loaded with Pd nanoparticles for 2-butyne-1,4-diol semi-hydrogenation in a continuous flow microwave reactor $\dagger$
}

\author{
Emanuela Calcio Gaudino, (DD a Maela Manzoli, (D) a Diego Carnaroglio, ${ }^{\text {ab }}$ Zhilin Wu, $^{a}$ \\ Giorgio Grillo, ${ }^{a}$ Laura Rotolo, ${ }^{a}{ }^{\prime}$ Jonathan Medlock, ${ }^{\mathrm{C}}$ Werner Bonrath ${ }^{\mathrm{c}}$ \\ and Giancarlo Cravotto (D) *a
}

A novel protocol for microwave-assisted alkyne semi-hydrogenation under heterogeneous catalysis in a continuous flow reactor is reported herein. This challenging task has been accomplished using a multifaceted strategy which includes the ultrasound-assisted preparation of Pd nanoparticles (average $\varnothing 3.0 \pm 0.5 \mathrm{~nm}$ ) that were synthesized on the $\mu$-metric pores of sintered alumina spheres $(\varnothing 0.8 \mathrm{~mm})$ and a continuous flow reaction under $\mathrm{H}_{2}$ (flow rate $7.5 \mathrm{~mL} \mathrm{~min}{ }^{-1}$ ) in a microwave reactor (counterpressure 4.5 bar). The semi-hydrogenation of 2-butyne-1,4-diol in ethanol was chosen as a model reaction for the purposes of optimization. The high catalyst efficiency of the process, in spite of the low $\mathrm{Pd}$ loading ( $\mathrm{Pd}$ content $111.15 \mathrm{mg} \mathrm{kg}^{-1}$ from ICP-MS), is due to the pivotal role of ultrasound in generating a regular distribution of $\mathrm{Pd}$ nanoparticles across the entire support surface. Ultrasound promotes the nucleation, rather than the growth, of crystalline $\mathrm{Pd}$ nanoparticles and does so within a particularly narrow Gaussian size distribution. High conversion (>90.5\%) and selectivity to (Z)-2-butene1,4-diol (95.20\%) have been achieved at an alkyne solution flow rate of $10 \mathrm{~mL} \mathrm{~min}{ }^{-1}$. The lead-free, alumina-stabilized Pd catalyst was fully characterized by TEM, HR-TEM, EDX, IR, XRPD and AAS. Highly dispersed $\mathrm{Pd}$ nanoparticles have proven themselves to be stable under the reaction conditions employed. The application of the method is subject to the dielectric properties of substrates and solvents, and is therefore hardly applicable to apolar alkynes. Considering the small volume of the reaction chamber, microwave-assisted flow hydrogenation has proven itself to be a safe procedure and one that is suitable for further scaling up to industrial application.

Received 11th January 2018

Accepted 7th February 2018

DOI: $10.1039 / c 8 \mathrm{ra00331a}$

rsc.li/rsc-advances

\section{Introduction}

The development of highly efficient and environmentally benign synthetic protocols is very much a central goal of current research in chemistry. Rational designs that can be scaled up for industrial use require careful multidisciplinary analyses of safety aspects and production costs. Of the non-conventional energy sources applied to process intensification, microwave (MW) irradiation, in combination with modern flow reactors, appears well set to fulfil all necessary safety, energy saving and scalability requirements.

\footnotetext{
${ }^{a}$ Dipartimento di Scienza e Tecnologia del Farmaco, NIS - Centre for Nanostructured Interfaces and Surfaces, University of Turin, Via P. Giuria 9, 10125 Turin, Italy. E-mail: giancarlo.cravotto@unito.it

${ }^{b}$ Milestone srl, Via Fatebenefratelli, 1-5, Sorisole 24010, Italy

'DSM Nutritional Products Ltd., Research and Development, PO Box 2676, 4002 Basel, Switzerland
}

$\dagger$ Electronic supplementary information (ESI) available. See DOI: $10.1039 / \mathrm{c} 8 \mathrm{ra00331a}$
Heterogeneous multiphase reactions with gaseous reagents in closed MW reactors have recently been shown to be viable alternatives to conventional protocols. The catalytic hydrogenation of unsaturated organic substrates is strongly influenced by homogeneous and heterogeneous catalysis, due to the fine control of selectivity offered by advances in catalyst design. ${ }^{1}$ Alkynes are a versatile class of compounds that are used by the fine chemical and pharmaceutical industries despite the fact that their selective and sustainable reduction is still a significant challenge. The typical industrial approach to alkyne semihydrogenation involves batch hydrogenation in the presence of the Lindlar catalyst (palladium on calcium carbonate, doped with lead, satisfactory alkene selectivity), ${ }^{2}$ which must be removed from the product stream at the end of the reaction, in a potentially hazardous procedure. Indeed, in addition to the presence of lead, that it is well known to be toxic, the employment of large amounts of amine modifier as well as the meticulous regulation of hydrogen are usually needed to fulfil an efficient process. $^{3}$ Such requirements imply severe 
disadvantages from safety, environmental and economic points of view. Therefore, routes to selective and environmentally benign alkyne reduction are highly sought after and research into new, suitable and sustainable heterogeneous catalysts is on-going. ${ }^{4}$ Heterogeneous catalysts offer significant advantages in reaction workup procedures and, in combination with continuous flow reactors, can furnish considerable benefits in an industrial context. ${ }^{5,6}$ In this frame, the possibility to work under more safe continuous-flow conditions can guarantee better catalytic performances and, at the same time, can decrease the number of processing steps. ${ }^{7}$ More in detail, the use of continuous flow reactors offers several advantages, such as the decrease of the purification steps and of the waste production, the reproducibility, the possibility to work with automatic operation, the decreased consumption of energy and the reduced space. ${ }^{8}$ All the above features contribute to the $E$ factor, that is expressed as the $\mathrm{kg}$ waste generated per $\mathrm{kg}$ product ratio, ${ }^{9}$ that significantly increase when using additives and other strategies in order to improve selectivity. Selective hydrogenations have already made good use of the particular properties of supported Pd nanoparticles (on active charcoal, ${ }^{\mathbf{1 0}}$ boehmite ${ }^{11}$ and polymers ${ }^{12}$ ). However, the design of an ideal catalytic green system for the semi-hydrogenation of alkynes under $\mathrm{H}_{2}$ pressure is still a challenging task. It is worth of note that different process parameters, such as productivity per unit active metal, volume or time, absence of additives or catalyst lifetime rule the choice on continuous-flow systems in alkyne hydrogenation at large-scale with respect to conventional batch reactors. ${ }^{13}$ Only a limited number of alkyne semihydrogenations in flow reactors has been reported in the literature. ${ }^{\mathbf{1 4}}$ These are usually carried out at very low flow rates by means of a HPLC pump ( $0.2 \mathrm{~mL} \mathrm{~min})$, as has recently been described by Pélisson et al. who made use of $15 \mathrm{~nm}$ sized Pd nanoparticles on porous monolithic silica, ${ }^{15}$ providing high activity and selectivity toward cis-alkene thanks to the presence of Pd plane surfaces on the nanoparticles. ${ }^{16}$ The conversion, selectivity and stereoselectivity of the alkyne hydrogenation were tuned using the flow rates of hydrogen and the substrate solution, leading to $80 \%$ conversion and $88 \%$ selectivity toward

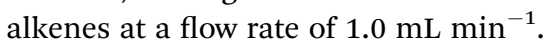

Moving on to catalyst production, Pd nanoparticles have been synthesized inside the hierarchical porosity of the homogeneous interconnected macropores $(4 \mu \mathrm{m})$ and mesopores $(11$ $\mathrm{nm}$ ) of silica monoliths and used as microreactors for the continuous selective hydrogenation of 3-hexyn-1-ol at room temperature. A constant conversion of $90.5 \%$ was observed, while only moderate selectivity to the cis isomer was achieved over a test period of $7 \mathrm{~h}$. This corresponds to a 10 fold increase in productivity over Lindlar-catalyst based batch production. ${ }^{17}$

Even the devices used for the hydrogenation reaction have been the subject of rapid design developments as the community aims to improve the performance of catalytic hydrogenation and fine tune selectivity to the semi-hydrogenated products. The integration of a solid heterogeneous catalyst into a microreactor entails difficulties that may either be overcome by employing a micro-packed bed of powdered catalyst, ${ }^{18}$ or by coating the inner walls of microchannels with a thin layer of catalyst. ${ }^{19}$ Unfortunately, high pressure drops can occur along the reaction-channels of a powdered catalyst micro packed-bed, whereas the volume of reactor channels is barely exploited by a thin catalyst coating. Capillary microreactors offer the possibility of controlling the reagent-catalyst contact time and temperature while also removing mass and heat transfer related limitations, providing this apparatus with the possibility of achieving high selectivity. ${ }^{18}$ In a separate development, a continuously working quartz capillary microreactor with a diameter of $250 \mu \mathrm{m}$ and a mesoporous-titanium-dioxide based catalytic coating with embedded Pd nanoparticles has been tested in the selective hydrogenation of 2-methyl-3-butyn-2-ol, giving $92.3 \%$ selectivity at $99.9 \%$ conversion to 2-methyl-3buten-2-ol at $40{ }^{\circ} \mathrm{C}$ in a pure hydrogen atmosphere. ${ }^{20}$ Selectivity was reported to be $15.5 \%$ higher than that found in a batch reactor and the hydrogenation rate was one order of magnitude higher than observed upon reaction with the commercial Lindlar catalyst.

In an even more recent study, a micro-reactor with 4 thin layers of catalyst powder separated by commercial nylon porous butyne on milled samples of a commercial egg-shell $\mathrm{Pd} / \mathrm{Al}_{2} \mathrm{O}_{3}$ catalyst. $^{21}$ Results were compared with those obtained in a conventional fixed bed reactor in the presence of the same catalyst. However, it was reported that the catalyst pellets were employed in their original size $(2.3 \mathrm{~mm}$ in diameter $)$ and therefore exhibited strong diffusional effects. The micro-reactor displayed a significant increase in catalytic activity (12.5 times greater) and selectivity while also proving to be appropriate for a reliable description of intrinsic reaction kinetics, which is essential for the design of industrial scale chemical reactors. A new falling film microstructured reactor was tested in the selective hydrogenation of 2-butyne-1,4-diol to its olefinic derivative. $1.1 \mathrm{wt} \%$ of $\mathrm{Pd}$ on $\mathrm{ZnO}$ gave $98 \%$ selectivity at 96\% conversion under optimized conditions with water as the solvent, which were close to the results of the benchmark reaction in batch mode. ${ }^{22}$

The wealth of possibilities currently available mean that using environmentally benign non-conventional enabling technologies to foster process intensification and combine safer protocols with cost reduction and energy savings is a promising strategy. ${ }^{23}$ Indeed, modern MW equipment provides easy, safe, rapid and efficient hydrogenation in the laboratory. ${ }^{24}$ Catalytic hydrogenation under MW irradiation has been conducted safely and quickly in open vessels, ${ }^{25}$ sealed reaction systems, ${ }^{26}$ a quartz reactor and even under 2.5 MPa of hydrogen pressure. ${ }^{27}$

Ultrasound (US)- and $\mathrm{MW}$-assisted protocols for catalyst preparation have been extensively reported in recent decades. ${ }^{28}$ In particular, US has been shown to enhance nucleation, ${ }^{29}$ leading to narrow metal particle size distributions which are ideal in catalyst preparation, ${ }^{30}$ while two supported Pd catalysts have been patented (on ceria ${ }^{31}$ and on boehmite ${ }^{32}$ ). These leadfree Pd-catalysts have been tested on a number of substrates providing selective conversion to alkenes under conventional conditions and, with improved results, under US and MW. ${ }^{33}$ Results achieved with a boehmite supported Pd catalyst, ${ }^{34}$ have provided the necessary background for the design of a new, USbased procedure for the preparation of highly dispersed, 
alumina-sphere stabilized Pd nanoparticles under nonconventional conditions, which is reported herein. The catalyst has been tested in the semi-hydrogenation of 2-butyne-1,4diol (ByD) to (Z)-2-butene-1,4-diol (BeD), which was chosen as the model reaction as BeD is an important chemical intermediate used in the production of vitamin $\mathrm{B} 6,{ }^{35}$ insecticides and fungicides, ${ }^{36}$ as well as being used in the paper, textile and resin industries. BeD is currently obtained commercially via the selective hydrogenation of 2-butyne-1,4-diol (ByD). The present study will therefore focus on the effect that MW irradiation has on ByD selective semi-hydrogenation in flow mode. Moreover, the main reaction parameters, such as substrate concentration, catalyst amount, temperature, hydrogen pressure, solvent type and volume, have all been investigated with an eye to process intensification and further scaling up. Investigations of this type are indispensable to the potential development of a pilot scale MW flow reactor for this process.

\section{Experimental section}

\section{Catalyst preparation}

All chemicals were purchased from Sigma-Aldrich and used without further purification. $\mathrm{Al}_{2} \mathrm{O}_{3}$ spheres were kindly provided by Fraunhofer ICT-IMM (Mainz, Germany). A commercial Lindlar catalyst (5\% Pd on calcium carbonate, poisoned by $\mathrm{Pb}$ additives) was purchased from Alfa-Aesar and used as the reference catalyst.

$\operatorname{Pd}(\mathrm{OAc})_{2}(120 \mathrm{mg})$ was suspended in $n$-propanol $(40 \mathrm{~mL})$ and sonicated in a cooled cup-horn apparatus (cavitating tube Danacamerini, Turin, $19.9 \mathrm{kHz}, 100 \mathrm{~W}$ ) for $10 \mathrm{~min}$ at $30{ }^{\circ} \mathrm{C}$. Sodium formate $(72 \mathrm{mg})$ and alumina spheres $(6 \mathrm{~g})$ were then added to the dispersion and sonicated for $30 \mathrm{~min}$ at $30{ }^{\circ} \mathrm{C}(19.9$ $\mathrm{kHz}, 100 \mathrm{~W}$ ). The sonicated mixture was stirred for $90 \mathrm{~min}$ at $80{ }^{\circ} \mathrm{C}$ (under conventional heating) and finally at room temperature (overnight). The recovered solid was filtered, washed with acetone and dried under vacuum. TGA analyses were performed on the as-synthesised catalyst, and no significant weight loss was observed (see Fig. SI-1 in the ESI + ), indicating that the acetone solvent was efficiently removed. Pd content of alumina-sphere was $111.15 \mathrm{mg} \mathrm{kg}^{-1}$ according to ICP-MS analysis recorded after final catalyst activation step. In this step the US prepared catalyst was flushed with ethanol $(25$ $\mathrm{mL} \min ^{-1}$ ) under MW irradiation at $65^{\circ} \mathrm{C}$ for $4 \mathrm{~min}$ within the MW FlowSYNTH reactor recording a $12 \%$ of metal leaching which remains unchanged even by prolonging the preactivation time up to $60 \mathrm{~min}$. This easy and fast procedure enabled a final Pd catalyst that showed a negligible metal leaching during the subsequent MW continuous-flow semi-hydrogenations (less than $0.1 \%$ as recorded by ICP-MS analysis after $240 \mathrm{~min}$ reaction).

\section{Catalyst characterisation}

Morphological characterization was initially performed using Scanning Electron Microscopy (SEM) on a ZEISS EVO 50 XVP microscope with $\mathrm{a} \mathrm{LaB}_{6}$ source, operating at $10 \mathrm{kV}$ and equipped with detectors for both secondary electron and back scattered electron collection. The samples were sputtered with a gold layer ( $c a .10 \mathrm{~nm}$ thickness, Bal-tec SCD050 sputter coater) prior to examination and particle size distribution was evaluated using SEM micrographs at $3000 \times$ and $5000 \times$ instrumental magnification by calculating the diameter size on more than 1000 nanoparticles. Gold coating thickness had no influence on the obtained values.

Structural characterization of the samples was carried out using a PW 3830/3020 X' Pert Diffractometer from PANalytical with a Bragg-Brentano module ( $\mathrm{Cu} \mathrm{K} \alpha$ radiation, $\lambda=1.5406 \AA)$ acquisition was performed in $0.02^{\circ}$ interval steps at $5 \mathrm{~s}$ per step in order to provide a good signal to noise ratio.

Transmission Electron Microscopy (TEM) and High Resolution (HR)-TEM analyses were carried out on both fresh and used catalysts using a side entry Jeol JEM 3010-UHR (300 kV) microscope equipped with a $\mathrm{LaB}_{6}$ filament. The synthesized samples were deposited on a copper grid, coated with a lacey carbon film for analysis. All digital micrographs were acquired using a $(2 \mathrm{k} \times 2 \mathrm{k})$-pixel Gatan US1000 CCD camera with an OXFORD INCA instrument for atomic recognition via energy dispersive X-ray spectroscopy (EDX).

A statistically representative number of crystallites $(>200$ nanoparticles) was counted in order to provide the particle size distribution, where the mean particle diameter $\left(d_{\mathrm{m}}\right)$ was calculated as; $d_{\mathrm{m}}=\Sigma d_{i} n_{i} / \Sigma n_{i}$, where $n_{i}$ was the number of particles of diameter $d_{i}$. Counting was carried out on electron micrographs obtained at a minimum of $150000 \times$ instrument magnification, meaning that Pd particle agglomerates were clearly visible against the support.

\section{General methods}

MW-promoted reactions were carried out in the FlowSYNTH reactor (Milestone Srl, Italy; MLS GmbH, Germany), a multimode system that operates at $2.45 \mathrm{GHz}$. This instrument was equipped with a vertical flow-through reactor, which can work up to a maximum of $200{ }^{\circ} \mathrm{C}$ temperature and 30 bar pressure and enables flow MW reactions to occur. 2-Butyne-1,4-diol (ByD) ethanol solution $(0.05 \mathrm{w} / \mathrm{v} \%)$ and $\mathrm{H}_{2}$ gas are pumped in from the bottom of the reactor (flow rate: $\mathrm{ByD}=10 \mathrm{~mL} \mathrm{~min}^{-1}$ and $\mathrm{H}_{2}$ $=7.5 \mathrm{~mL} \mathrm{m^{-1 }}$; residence time: $60 \mathrm{~s}$ ) and reaction products flow out the top into a water-cooled heat exchanger. Indeed the hydrogen flow rate has been measured with a mass flowmeter as $\mathrm{N} \mathrm{mL} \mathrm{min}^{-1}$. For the sake of simplicity, it will be reported as $\mathrm{mL} \mathrm{min}^{-1}$ in the whole text. A high-performance polymer shield and a back-pressure control valve help to provide safe conditions in the PTFE-TFM flow-through reactor at all times. Moreover, integrated reactor sensors continuously monitored the internal pressure, temperature and power applied inside the reactor cavity for each reaction run and adjusted the applied MW power in real time to follow the predefined temperature profile. This system enables reactions to be scaled-up from grams to kilograms.

Aliquots $(100 \mu \mathrm{L})$ of the solution were periodically extracted from the reaction, diluted with $900 \mu \mathrm{L}$ chloroform and analysed using GC-MS. The analyses were carried out in a gas chromatograph Agilent 6890 (Agilent Technologies, USA) fitted with 
a mass detector Agilent Network 5973 using a capillary column that was $30 \mathrm{~m}$ long and had an i.d. of $0.25 \mathrm{~mm}$ and a film thickness of $0.25 \mathrm{~mm}$. GC conditions were as follows; injection split of $1: 20$, injector temperature of $250{ }^{\circ} \mathrm{C}$ and detector temperature of $280{ }^{\circ} \mathrm{C}$. The gas carrier was helium $(1.2$ $\left.\mathrm{mL} \min ^{-1}\right)$, and the temperature program proceeded from $70{ }^{\circ} \mathrm{C}$ $(2 \mathrm{~min})$ to $300{ }^{\circ} \mathrm{C}$ at a rate of $5{ }^{\circ} \mathrm{C} \mathrm{min}^{-1}$.

\section{General reaction conditions for 2-butyne-1,4-diol semi- hydrogenation}

ByD is a colourless, hygroscopic organic compound that is soluble in water and polar organic solvents. It is often applied as a model compound for the study of the selective hydrogenation of polar alkynes. ${ }^{37}$ The reaction was performed under MW irradiation in flow mode. The reactor cartridge $(20 \mathrm{~mL})$ was filled with Pd-loaded alumina spheres (6 g) and with inert materials (3-8 mm Ø Pyrex glass spheres $10 \mathrm{~g}$ ) giving a residual reactor volume of $10 \mathrm{~mL}$. The liquid/gas reaction mixture, the ByD ethanol solution $(0.05 \mathrm{w} / \mathrm{v} \%)$ and $\mathrm{H}_{2}\left(7.5 \mathrm{~mL} \mathrm{~min}{ }^{-1}\right)$, was pumped through the reactor $\left(10 \mathrm{~mL} \mathrm{~min}^{-1}\right)$ under $\mathrm{MW}$ irradiation $\left(350 \mathrm{~W}\right.$, reaction temperature $\left.65^{\circ} \mathrm{C}\right)$. The FlowSYNTH work station enabled all of the key parameters to be precisely monitored. Reaction work up only involved solvent evaporation and direct GC-MS analysis (1 $\left.\mathrm{mg} \mathrm{mL}^{-1} \mathrm{EtOH} / \mathrm{CHCl}_{3} 9: 1\right)$.

\section{Results and discussion}

Designing a new synthetic procedure for highly dispersed, alumina-sphere stabilized Pd nanoparticles under sonochemical conditions

Our previous results on alkyne semi-hydrogenation in both batch and flow modes with a boehmite supported Pd catalyst, ${ }^{34,38}$ were the base upon which we designed a new USassisted procedure for the production of alumina-sphere stabilized Pd nanoparticles (Scheme 1). $\mathrm{Pd}(\mathrm{AcO})_{2}$ was used as the precursor for the new heterogeneous $\mathrm{Pd}-\mathrm{Al}_{2} \mathrm{O}_{3}$ catalyst

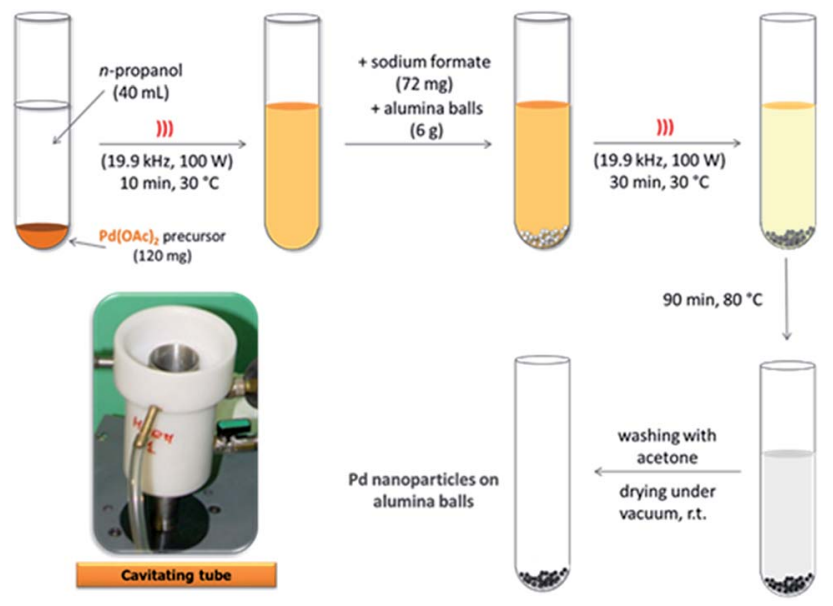

Scheme 1 Synthetic US-assisted procedure for the preparation of highly dispersed, alumina-sphere stabilized Pd nanoparticles. which was prepared via the impregnation technique according to a two-step protocol.

After the initial US-assisted dispersion of $\mathrm{Pd}(\mathrm{OAc})_{2}$ in $n$ propanol $(19.9 \mathrm{kHz}, 100 \mathrm{~W})$, the reduction of $\mathrm{Pd}(\mathrm{OAc})_{2}$ was performed under US $\left(30 \mathrm{~min}, 30^{\circ} \mathrm{C}\right)$ and in the presence of sodium formate and alumina spheres. The final impregnation step was subsequently conduced at $80{ }^{\circ} \mathrm{C}$ ( $90 \mathrm{~min}$ conventional heating). Acoustic cavitation was used as it is able to promote the rapid dispersion of solids and facilitate the formation of porous materials and nanostructures while also inhibiting particle aggregation.

\section{ByD selective semi-hydrogenation in flow mode under MW irradiation}

The alumina-sphere stabilized Pd nanoparticles obtained (see also Catalyst section) were then tested in the selective semihydrogenation of ByD. It is often used as a model compound for the study of the selective hydrogenation of alkynes. ${ }^{37 b}$

In previous works we have compared a variety of conventional conductive heating and volumetric dielectric heating protocols for the selective hydrogenation of ByD (Scheme 2). ${ }^{33}$

As a matter of fact, specific and selective activation of the solid catalyst surface means that dielectric heating can dramatically enhance reaction rate and selectivity. ${ }^{39}$

Experiments started with reactions in a batch reactor (SynthWAVE, Milestone, Italy), before continuing with flow systems (FlowSYNTH, Milestone, Italy), always with an eye to facilitating industrial scale-up. Indeed, new alumina-sphere stabilised, Pdnanoparticle based catalytic systems can be viewed as complementary to our previously reported, Pd heterogeneous system (Pd supported on boehmite) in which ByD was selectively hydrogenated in water under $\mathrm{MW}$ irradiation at $90{ }^{\circ} \mathrm{C}$ in only $30 \mathrm{~min}$ (conv. $=100 \%$, selec. $=92 \%$ ). ${ }^{33}$

A versatile MW flow device was used to assess the performance of this catalyst under continuous flow conditions. The heterogeneous-catalyst containing reactor chamber was fixed vertically inside the multimode MW cavity. A schematic representation of the arrangement of the catalytic material inside the reaction chamber is shown in Fig. 1.

In this configuration, the reactor enabled the simultaneous, rising flow of both liquids and gases to occur through the reactor, even under pressure. The flowing stream is then decompressed and the products are collected free from the catalyst. A scheme of the reactor used for alkyne semihydrogenation is depicted in Fig. 2a, whereas the overall MW set up is schematically reported in section b of the same figure.

The system consists of a MW lab station with a maximum power setting of $1000 \mathrm{~W}$, equipped with a vertical flow-through

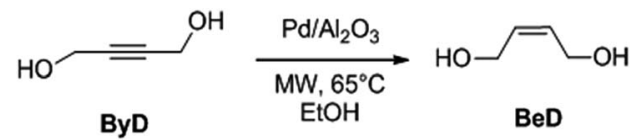

Scheme 2 MW flow ByD semi-hydrogenation to (Z)-BeD on $\mathrm{Pd} / \mathrm{Al}_{2} \mathrm{O}_{3}$ catalyst. 

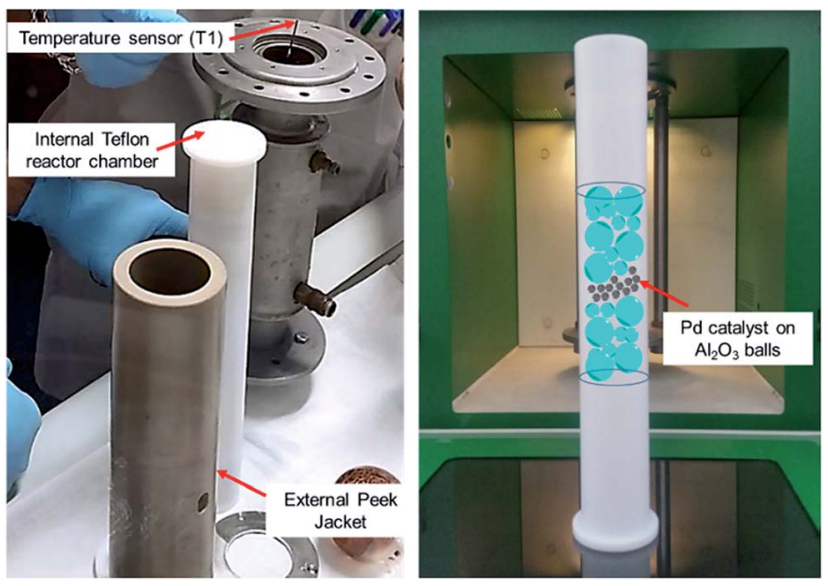

Fig. 1 A schematic representation of the arrangement of the aluminasphere stabilised $\mathrm{Pd}$ catalyst inside $\mathrm{MW}$ reaction chamber.

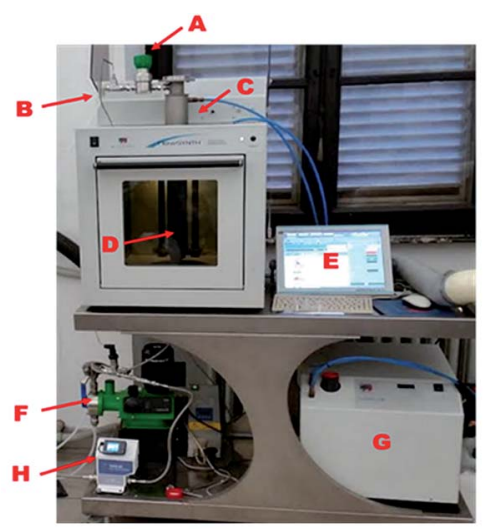

a

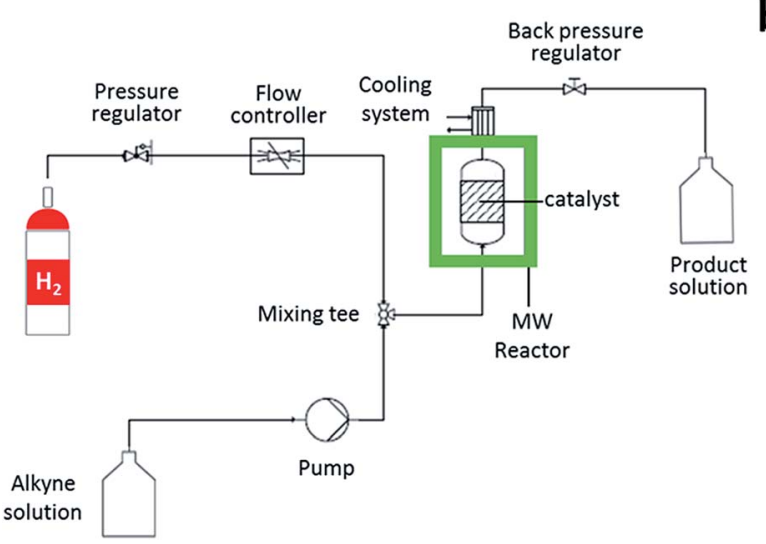

b

Fig. 2 (a) MW flow reactor for alkyne semi-hydrogenation. (b) Scheme of MW continuous flow reactor setup for liquid-phase catalytic alkyne hydrogenation reaction.

Teflon (TFM) reactor (max volume $20 \mathrm{~mL}$ ). The reaction product came out from the top of reactor into a water-cooled heat exchanger and sampled every $10 \mathrm{~min}$ for further GC-MS analyses. Reaction temperature was monitored continuously by inline thermocouple sensors at the top of the reactor. An external touchscreen terminal was used to monitor and control all process conditions. In order to achieve best conversion and selectivity in term of $(Z)-\mathrm{BeD}$, different residence times were explored to gain the optimized conditions of semihydrogenation (30-120 s), related to different ByD solution flow rates $\left(5-20 \mathrm{~mL} \mathrm{~min}{ }^{-1}\right.$ ) (best result achieved for $60 \mathrm{~s}$ of residence time and $10 \mathrm{~mL} \mathrm{~min}^{-1}$ of alkyne flow).

The combination of the described MW reactor and the alumina-sphere stabilised Pd catalyst (0.012 wt\% Pd), was able to selectively hydrogenate ByD under continuous flow and produce BeD as the only reaction product. It is worth noting that the selectivity $(S)$ data reported in the following, were obtained as $(Z)$-2-butene-1,4-diol (BeD)/butane-1,4-diol (BaD) ratio.

In detail, a solution of ByD (ethanol solution (0.05 w/v\%), flow rate $=10 \mathrm{~mL} \mathrm{~min}^{-1}$ ), flowed inside the MW reactor with hydrogen (gas flow rate $=7.5 \mathrm{~mL} \mathrm{~min}^{-1}$ ) under a total pressure of 4.5 bar, giving almost full ByD conversion $(C$ : $>90.5 \%)$ over $15 \mathrm{~min}$ of $\mathrm{MW}$ irradiation at $65{ }^{\circ} \mathrm{C}$ and good selectivity $(S$ : $95.20 \%$ ) towards BeD. The same results were produced continuously over 4 hours of MW flow hydrogenation under the same conditions, processing a total of $2.4 \mathrm{~L}$ of ByD solution (Fig. 3).

The substrate solution flow rate could be increased up to 15 $\mathrm{mL} \min ^{-1}$ with minimal conversion and selectivity losses $(C$ : $76 \%, S: 87 \%)$. However, a sharp drop in conversion was observed $(C: 33 \%)$ when the ByD flow rate was further increased (up to $20 \mathrm{~mL} \mathrm{~min}^{-1}$ ), halving residence times. $10 \mathrm{~mL} \mathrm{~min}^{-1}$ was thus decided to be the proper liquid flow rate (Fig. 4).

Catalyst stability and reusability were then evaluated: the Pd nanoparticle stabilization is a key factor to limit the metal leaching in solution during the semi hydrogenation (an issue of utmost importance for the reduction of metal residues in the food and pharmaceuticals manufacture industry). ${ }^{5}$ In this frame, the original ByD ethanol solution $(0.05 \mathrm{w} / \mathrm{v} \%)$ was again fluxed through the reactor over the same catalyst. Gradual catalyst deactivation was observed only after $20 \mathrm{~L}$ of flow reduction (substrate solution flow rate $=10 \mathrm{~mL} \min ^{-1} ; \mathrm{H}_{2}$ flow $=7.5 \mathrm{~mL} \mathrm{~min}^{-1}$ ).

The alumina spheres employed in this work, due to the surface morphology, have proved to be very effective in supporting and stabilizing the Pd nanoparticles produced under sonication. It is worth of note that no metal scavengers located as downstream cartridge were required to abate metal contamination during semi-hydrogenation due to the negligible metal leaching of the used catalyst.

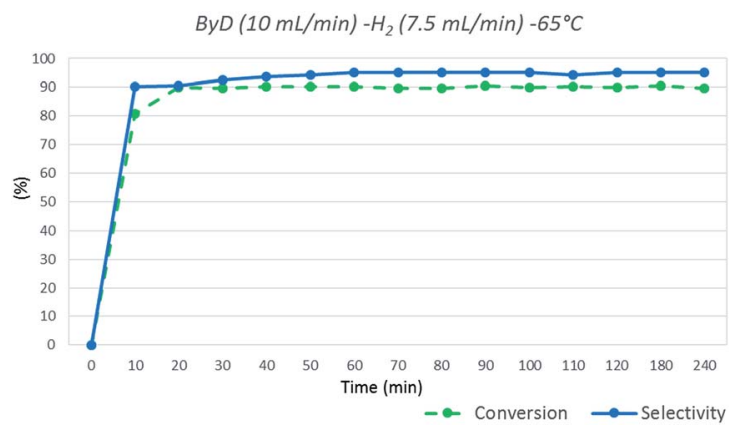

Fig. 3 ByD flow semi-hydrogenation $\left(10 \mathrm{~mL} \mathrm{~min}{ }^{-1}\right)$ at $65^{\circ} \mathrm{C}$ and 7.5 $\left(\mathrm{mL} \mathrm{min}^{-1}\right) \mathrm{H}_{2}$ flow and 4.5 bar total pressure. 


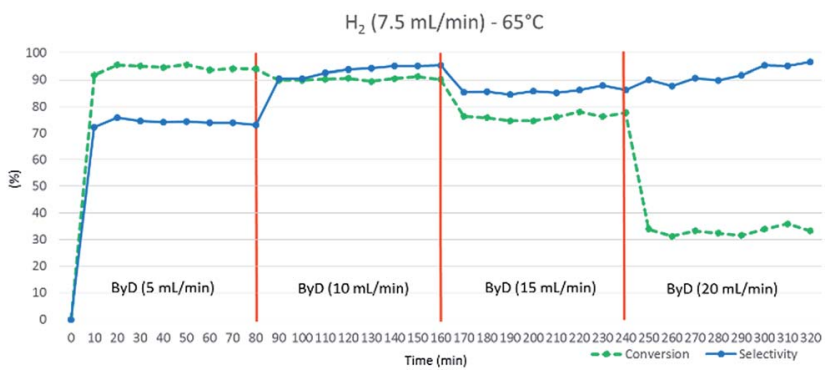

Fig. 4 Influence of ByD flow rate on (Z)-BeD conversion and selectivity at $65^{\circ} \mathrm{C}, 7.5\left(\mathrm{~mL} \mathrm{~min}^{-1}\right) \mathrm{H}_{2}$ flow and 4.5 bar total pressure.

Hydrogen flow and total $\mathrm{H}_{2}$ pressure also clearly influenced ByD conversion under MW. Indeed, a drastic reduction in ByD conversion was recorded ( $C: 28 \%$ ) (Fig. 5a) when a ByD ethanol solution $\left((0.05 \mathrm{w} / \mathrm{v} \%)\right.$, flow rate $\left.=10 \mathrm{~mL} \mathrm{~min}^{-1}\right)$ was passed over the catalyst at $65{ }^{\circ} \mathrm{C}$, together with hydrogen (gas flow $7.5 \mathrm{~mL} \mathrm{~min}^{-1}$ ) at a total pressure of 1.5 bar, instead of 4.5 bar. No ByD conversion was obtained when reactor counter-pressure

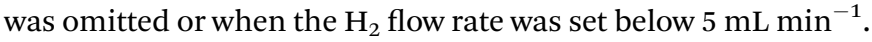
Furthermore, total $\mathrm{H}_{2}$ pressure values of above 7.5 bar and total

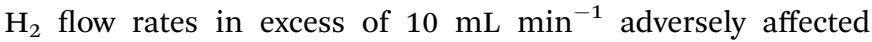
selectivity towards $(Z)$-BeD (S: 78\% and 30\%, respectively) due to the over-hydrogenation phenomena which occur under these conditions, probably due to an enhanced residence time of the mixture inside the reactor (Fig. 5, sections a and b). At higher $\mathrm{H}_{2}$ flow rates $\left(10 \mathrm{~mL} \mathrm{~min}^{-1}\right)$ perhaps incomplete gas dissolution or preferential paths throw the catalyst bed negatively affected the conversion.

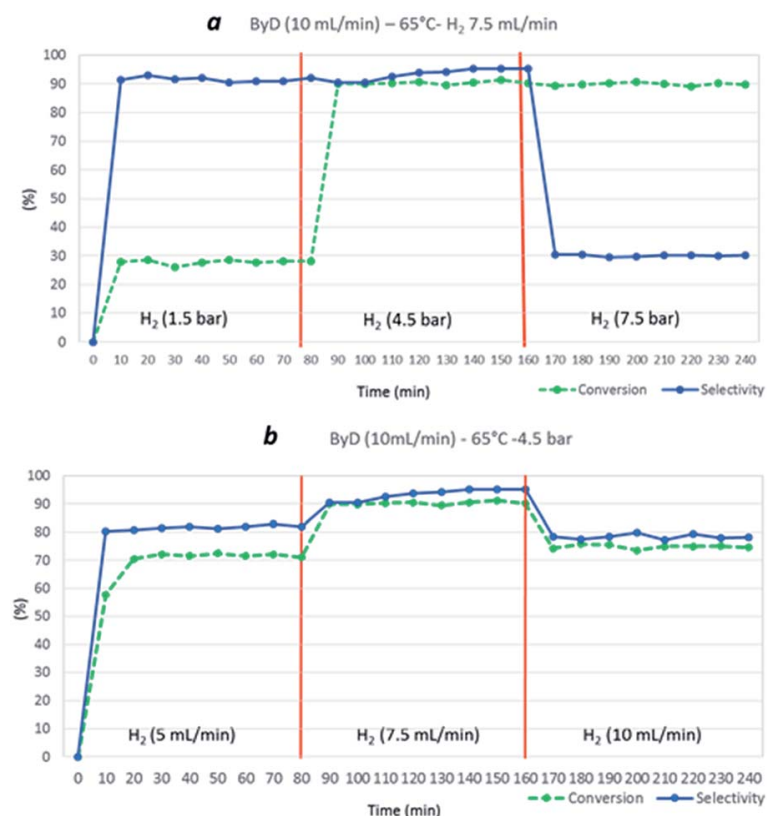

Fig. 5 Influence of $\mathrm{H}_{2}$ total pressure (at a $\mathrm{H}_{2}$ flow rate of $7.5 \mathrm{~mL} \mathrm{~min}^{-1}$ ) (a) and influence of $\mathrm{H}_{2}$ flow rate (at 4.5 bar) (b) on ByD conversion and selectivity to $(Z)-\mathrm{BeD}$ at $65{ }^{\circ} \mathrm{C}$, over a total $\mathrm{ByD}$ flow rate of 10 $\mathrm{mL} \min ^{-1}$

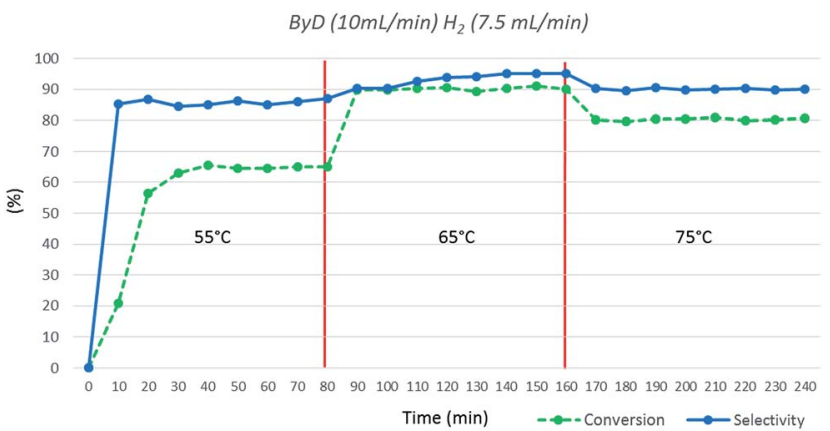

Fig. 6 Influence of temperature on ByD conversion and selectivity to (Z)-BeD under MW irradiation (ByD (10 $\mathrm{mL} \mathrm{min}^{-1}$ ) and $\mathrm{H}_{2} \quad(7.5$ $\left.\mathrm{mL} \mathrm{min}^{-1}\right)$ ) and 4.5 bar of total pressure.

Finally, the influence of temperature was investigated; very poor conversions were observed at $55{ }^{\circ} \mathrm{C}(C: 63 \%)$, whereas $65{ }^{\circ} \mathrm{C}$ appears to be the optimal choice. Moreover, conversion and selectivity toward BeD dropped (C: $81 \% ; S: 90 \%)$ upon increasing the temperature to $75^{\circ} \mathrm{C}$ (Fig. 6).

The dielectric properties of ethanol allowed for fast and selective heating to be carried out, while also having an effect on the catalyst surface and alkene adsorption-dissociation phenomena. The fact that the dissociation of the formed alkene is a key feature of reaching high conversions in semihydrogenations is now well-documented in the literature. ${ }^{\mathbf{4 0}}$ The catalytic results can be qualitatively explained using the classical model proposed by Bond ${ }^{\mathbf{1 6}}$ which can be adapted for the hydrogenation of substituted alkynes in a liquid phase, according to Scheme 3.

Selectivity in alkyne hydrogenation is governed by two alternative possible reaction paths, named (i) mechanistic and (ii) thermodynamic factors. In the mechanistic path, a chemisorbed alkene intermediate (BeD) is adsorbed onto the surface for enough time to be hydrogenated to the $\mathrm{BaD}$ alkane, as shown in step (3), whereas, in the thermodynamic process, the alkene can desorb and then subsequently re-adsorb in competition with the alkyne molecules, according to step (2).

In the hydrogenation of ByD under continuous MW flow conditions, the Pd catalyst showed almost full conversion and good selectivity ( $C: 90.5 \% ; S: 95.2 \%$ ) towards BeD, even at the early stage of the reaction when conversion is low and the readsorption of alkene at step (2) (thermodynamic factor) can be neglected (initial selectivity).

Both conversion and selectivity remained constant for over 4

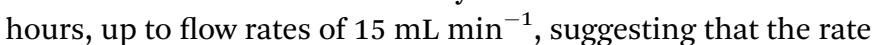
of alkene desorption dominates the rate of hydrogenation of the

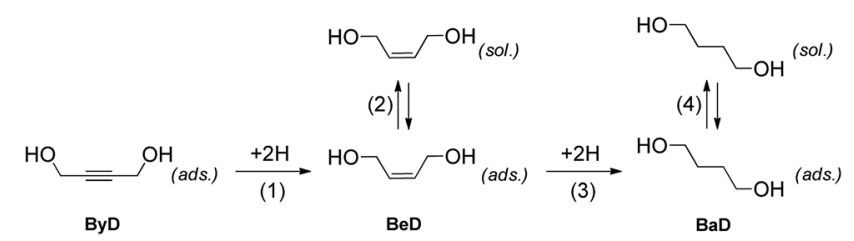

Scheme 3 
adsorbed alkene intermediate, which improves initial alkene selectivity. A further increase in flow rate, of up to $20 \mathrm{~mL} \mathrm{~min}^{-1}$, did not produce any improvements in catalytic activity, confirming the key role played by contact time.

The fundamental role of dielectric heating on the reaction rate was confirmed by a comparative test under optimized conditions of temperature, pressure, liquid/gas flow rate, using a preheated alkyne solution $\left(65-67^{\circ} \mathrm{C}\right)$ pumped in the same reactor without MW irradiation. All the samples analysed showed a negligible conversion (less than 15\%).

Present results indicate that MW irradiation impact the overall catalytic process. ${ }^{41}$

\section{Catalyst characterization}

According to Fig. SI-2 reported in the ESI, $\uparrow$ the alumina-based spheres used as support for the active phase have an average size of $0.8 \mathrm{~mm}$ (section a) and display a reasonably regular spherical shape (section b). The EDX elemental analysis revealed that other elements $(\mathrm{Mg}, \mathrm{Si}, \mathrm{Ca})$ are present besides $\mathrm{Al}$ and $\mathrm{O}$, which are the principal components. X-ray powder diffraction analysis (reported in section a of Fig. SI-3†) revealed the highly crystalline nature of the spheres which are mainly made up of the $\mathrm{Al}_{2} \mathrm{O}_{3}$ rhombohedral phase (JCPDS file number 00-001-1296), but also include smaller amounts of orthorhombic $\mathrm{MgSiO}_{3}$ (JCPDS file number 00-003-0519), $\mathrm{MgSiO}_{4}$ (JCPDS file number 00-034-0189), monoclinic $\mathrm{Mg}$ and $\mathrm{Al}$ oxide (JCPDS file number 00-010-0238). These results are in agreement with EDX data that highlighted the presence of $\mathrm{Mg}$ and $\mathrm{Si}$ (Fig. SI-2, $\dagger$ section c). Moreover, no crystalline-Pd-related peaks were observed upon the addition of the metal (section $b$, the dashed line indicates the position of the main cubic Pd crystalline phase peak at 2 theta $=40.581$ ), which is due to the very low amounts of metal present.

Interestingly, a closer inspection of SEM images at higher magnifications revealed that the sphere surface is indeed rough, as shown in section a of Fig. SI-4, $\dagger$ and that this texture is caused by the presence of small particles (section $b$ of the same figure), that were probably sintered by the high temperature reached during spheres synthesis. The most significant sintered particle fraction displays a size of around $0.25 \mu \mathrm{m}$ while average measured size is $0.4 \pm 0.2 \mu \mathrm{m}$, as shown in section c.

The surface of the alumina spheres is shown, after Pd impregnation, in Fig. SI-5. $\dagger$ The SEM investigation demonstrated that the Pd agglomerates preferentially locate inside the recesses created by the sintered alumina particles (black zones). Moreover, the TEM measurements also confirmed the presence of Pd particle agglomerates (section b) indicating that the predispersion of the Pd precursor by US led to the formation of Pd nanoparticles on the alumina microspheres.

HRTEM analyses were carried out on both fresh and used catalyst in order to provide further insight into the metal phase. It was found that Pd is exclusively present as spherically shaped nanoparticles, as shown in Fig. 7 section a, and that they display homogeneous size, as demonstrated by the quite narrow particle size distribution reported in section $\mathrm{c}$ of the same figure. Indeed, analyses provided an average diameter of $3.0 \pm$ $0.5 \mathrm{~nm}$ for the spherical Pd nanoparticles. The crystalline nature of the Pd nanoparticles was also investigated by measuring the distances between the points defined by the diffracted electrons and transmitted beam in the corresponding Fourier transform (FT) of the whole range of HR-TEM micrograph images. The FT displayed a typical ring pattern of randomly oriented particles, in which some individual reflections can be also discerned (see section b of Fig. 7). Interestingly, the only reflection observed was at $0.194 \mathrm{~nm}$, which is related to the (200) plane of metallic Pd in the cubic crystalline phase (JCPDS file number 00-046-1043).

\section{Structure-activity relationships}

HR-TEM findings indicate that US promoted the formation of high purity Pd nanoparticles with uniform shape and narrow size distribution at low crystallization temperatures.

These results strongly indicate that Pd nanoparticle formation is dominated by a nucleation and growth mechanism. It can be proposed that the formation of Pd nanoparticles in the first step of the synthesis involves the creation of a complex
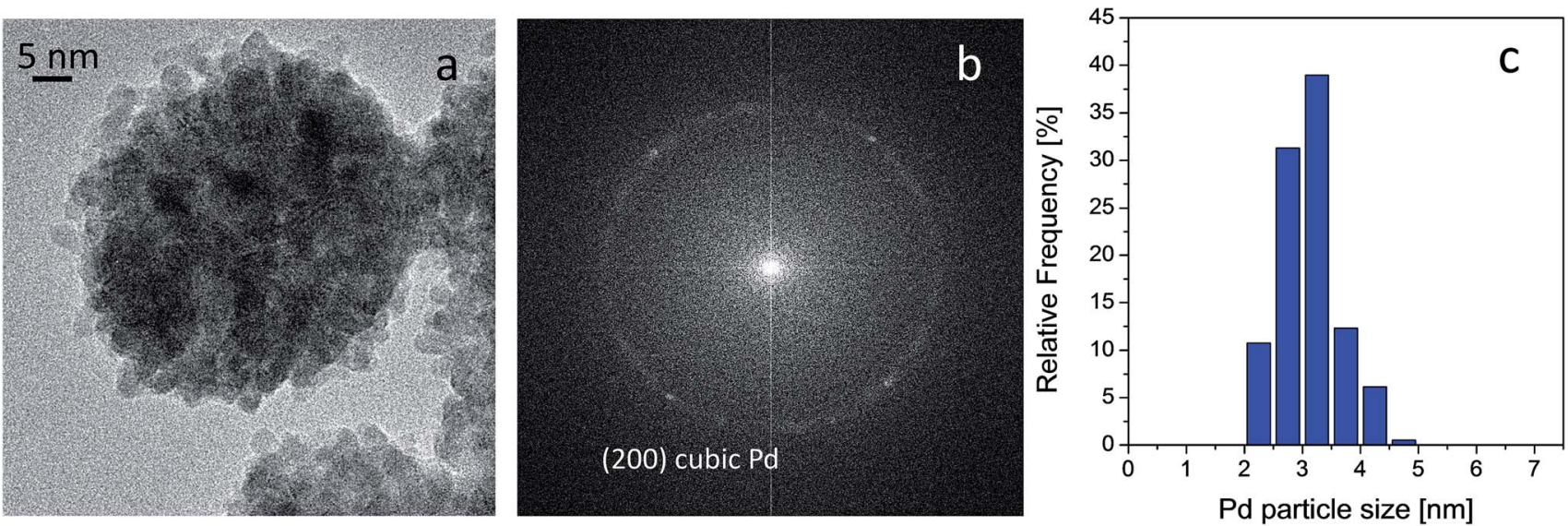

Fig. 7 HRTEM image of the fresh Pd catalyst (a), FFT of the image reported in section a (b) and Pd particle size distribution (c). Instrumental magnification $300000 \times$. 
amorphous phase network which we assume involves palladium cations creating $\mathrm{Pd}(\mathrm{OH})^{+}$species in the $n$-propanol solution. A gel, made up of an entangled complex network of Pd hydroxide chains, is thought to take form. The second step of the synthesis involves the nucleation of primary crystalline Pd nanoparticles under sonochemical conditions.

Indeed, the microjet effect in the liquid medium generated extreme synthesis conditions (hot spots with high temperature $\sim 5000 \mathrm{~K}$, pressure $\sim 20 \mathrm{MPa}$ and a very high cooling rate $\left.\sim 10^{10} \mathrm{~K} \mathrm{~s}^{-1}\right),{ }^{42}$ resulting in a reactant solubility enhancement which augmented the supersaturation of the reactant solution.

The nucleation process was quickened by the implosive bubble collapse, whilst the crystal growth process was somewhat hindered and slowed by the shock waves and turbulent flow created by the ultrasonic waves, ${ }^{43}$ which therefore promoted nucleation over grain growth to form tiny primary nanoparticles.

Almost perfectly spherical nanoparticles with a narrow size distribution were then formed in the third synthesis stage. The turbulent flow and mechanical effects created a relatively uniform reaction in the fluid medium and can improve the spherical shape of the Pd nanoparticles. ${ }^{43}$ High-speed microjets (over $400 \mathrm{~km} \mathrm{~h}^{-1}$ ) put pressure on the aggregated cluster from all directions meaning that crystalline nanoparticles are driven together at extremely high speeds, thus inducing effective melting at the point of impact and generating nanoparticles with a narrow size distribution. Pd nanoparticle decorated $\mathrm{MoS}_{2}$ nanosheets with high homogeneity and good dispersity have very recently been synthesised via a simple and efficient sonochemical method. ${ }^{\mathbf{4 4}}$ The composites exhibited better electrocatalytic activity, in an oxygen electroreduction, than the commercial Pt catalyst, highlighting the effectiveness of the sonochemical approach for the facile preparation of high quality supported metal nanoparticles.

Some concepts should, perhaps, be clarified before attempting to explain the remarkable catalytic activity and selectivity displayed by these highly dispersed, crystalline and uniformly shaped Pd nanoparticles. Indeed, the crystallographic orientation of the surfaces has a strong impact on the catalytic activity. Significant differences in activity and selectivity in a number of palladium nanoparticle catalysed de-hydrogenation, ${ }^{45}$ and hydrogenation reactions have been reported in the literature. Both reaction classes are surfacesensitive, that is to say that the catalytic activity depends on the crystallographic orientation of the surface, i.e. Pd (110) is much more active than (111). ${ }^{46}$ In addition, also the abundance of the Pd (200) phase can influence the catalytic performance. ${ }^{45}$ Generally, Pd nanoparticles exhibit facets of different crystallographic orientation [e.g. (111) and (100)], meaning that variations in the relative abundances of the facets with particle size are able to influence overall catalytic activity, as the different facets exhibit different activity.

Kiwi-Minsker et al. have investigated the solution phase selective hydrogenation of alkynes over stabilized Pd nanocrystals and indicated that the semi-hydrogenation of 2-methyl-3-butyne-2-ol to 2-methyl-3-butene-2-ol is also structure sensitive. ${ }^{47}$ Computational and experimental modelling have been used to investigate the structure sensitivity of 2methyl-3-butyne-2-ol hydrogenation over Pd. ${ }^{48}$ Further studies into supported Pd nanoparticles for acetylene gas phase hydrogenation have highlighted the fact that both Pd size and shape can significantly influence catalytic performance. ${ }^{49}$ In particular, acetylene hydrogenation also gave rise to ethane, in addition to ethylene, which may have either resulted from further ethylene hydrogenation or direct acetylene hydrogenation. It was observed that octahedrally shaped palladium particles were the most active as they only contain (111) facets, whereas cubically shaped Pd particles, which consists of only (100) facets, displayed low activity. Pd particles of cuboctahedral shape, which contain facets of both types, showed intermediate activity. It was found that alkynes are more strongly adsorbed onto palladium than alkenes or alkanes. ${ }^{50}$ This feature explains the selectivity displayed by Pd catalysts in the hydrogenation of a triple bond. Moreover, alkene adsorption onto a Pd surface should not be so strong that it prevents the reaction from proceeding sufficiently rapidly. It was found that Pd (111) was more active than Pd (100), and it was assumed that acetylene is more strongly adsorbed onto (100) faces, which would mean that hydrogenation reactions occur more slowly on (100) than on (111) faces. ${ }^{50}$

The metal nanoparticles with a diameter of $3.0 \mathrm{~nm}$, in the present catalytic system, have a reasonable preponderance of $\mathrm{Pd}$ atoms in the (200) plane which are in equilibrium with the complex liquid phase, whereas Pd particles in conventional catalysts generally have a broader size distribution and, therefore, a higher concentration of atoms in the (111) plane. A doubly positive effect may result from the presence of the (200) plane: on one hand, the dissociative adsorption of $\mathrm{H}_{2}$, which would form highly active atomic hydrogen species that could reduce the alkyne, most likely occurs less rapidly on these Pd (200) planes than on the (111) plane. This would appear to be in agreement with literature results that show differing reactivity for the two crystalline planes in accordance with the so-called geometric effect, in which the relative amounts of different surface atoms types and particle size influence activity; on the other hand, the smaller distance of the (200) plane with respect to that of the (111) plane (1.94 $\AA$ vs. $2.24 \AA)$, may mean that the alkyne is more strongly adsorbed onto the Pd (200) planes than the (100) faces, by means of a more effective interaction between Pd d orbitals and alkyne molecular orbitals (electronic effect). This may explain the high selectivity to BeD displayed by the Pd catalyst.

\section{On catalyst stability}

Small, crystalline Pd nanoparticles of homogeneous size were still observed on the used catalyst, as seen in Fig. 8, sections $\mathrm{a}$ and $\mathrm{b}$. The particle size distribution indicated that very limited Pd nanoparticle agglomeration occurred during reaction. Indeed, the used catalyst was analysed after $20 \mathrm{~L}$ of ByD semihydrogenation under the following conditions: ByD (0.05 $\mathrm{w} / \mathrm{v} \%)=10 \mathrm{~mL} \min ^{-1}, \mathrm{H}_{2}=7.5 \mathrm{~mL} \min ^{-1}\left(4.5 \mathrm{bar}, 65^{\circ} \mathrm{C}\right)$. An average $\mathrm{Pd}$ diameter of $4.2 \pm 0.7 \mathrm{~nm}$ which gave a stable $\mathrm{Pd}$ active phase despite severe reaction conditions in which 

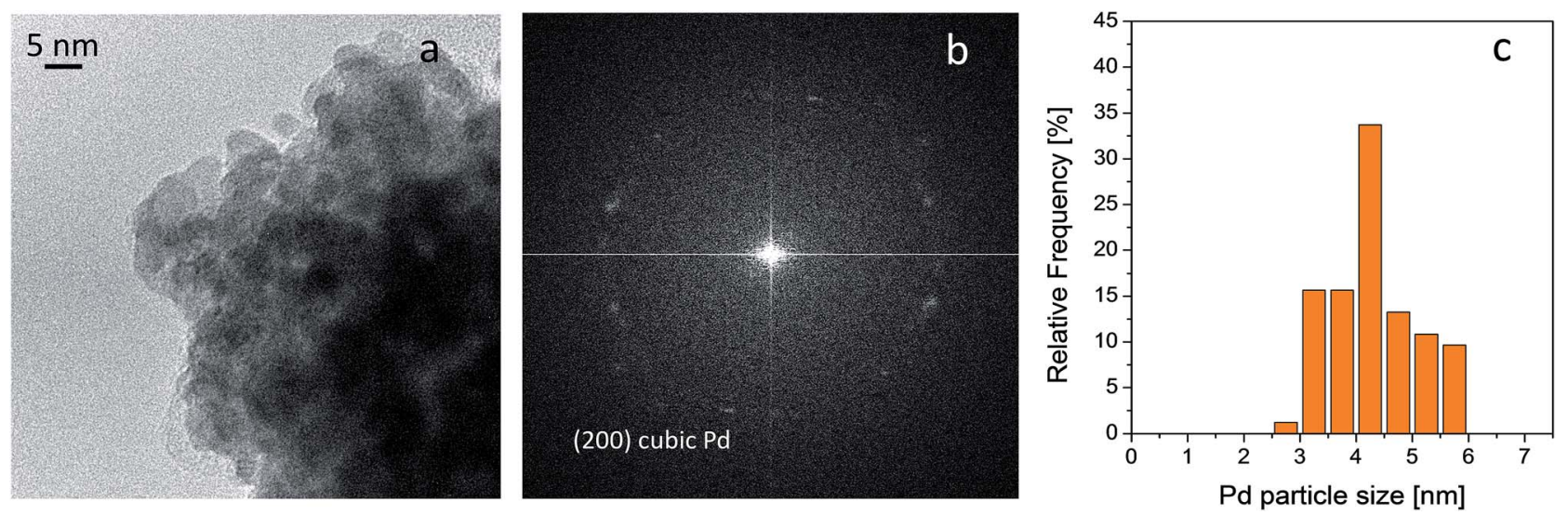

Fig. 8 HRTEM image of used Pd catalyst (a), FFT of the image reported in section a (b) and Pd particle size distribution (c). Instrumental magnification $300000 \times$

continuous flow and MW irradiation were combined. In this frame, the high intrinsic surface energy meant that the highly dispersed Pd nanoparticles tended to aggregate into large particles whose stability can be expressed as follows: ${ }^{51}$

$$
S=\left(R_{\mathrm{a}}+R_{\mathrm{b}}\right) \int_{R_{\mathrm{a}}-R_{\mathrm{b}}}^{\infty} \exp \left[\frac{V(c)}{k_{\mathrm{B}} T}\right] \frac{\mathrm{d} C}{C^{2}}
$$

where $S$ is the stability factor of the particles, $R_{\mathrm{a}}$ and $R_{\mathrm{b}}$ are the radii of the two particles, $V(c)$ is the function of potential energy interaction, $C$ is the distance between the two particles, $k_{\mathrm{B}}$ is the Boltzmann's constant $\left(1.3806 \times 10^{-23} \mathrm{~J} \mathrm{~K}^{-1}\right)$ and $T$ is the temperature $(\mathrm{K})$. When the distance between particles is decreased to a certain extent, i.e. under flow and MW irradiation, short-range interactions (van der Waal's forces and the existence of an electrostatic barrier) lead to strong attraction between particles, resulting in particle aggregation and a further increase in average particle size. HR-TEM results would appear to indicate that aggregation into large particles is negligible which highlights the impressive stability of the Pd nanoparticles synthesised in this new US-assisted procedure.

\section{Scalability of the process}

The process scalability was finally evaluated for the ByD semihydrogenation under the optimized reaction condition (alkyne flow rate $=10 \mathrm{~mL} \mathrm{~min}{ }^{-1} ; \mathrm{H}_{2}$ flow rate $=7.5 \mathrm{~mL} \mathrm{~min}^{-1}$; total pressure $=4.5 \mathrm{bar}$ ) in order to establish a proper comparison. The starting ByD amount $(0.05 \mathrm{w} / \mathrm{v} \%)$ in the reacting mixture was increased up to $5 \%$ and its selective MW flow hydrogenation was assessed over $60 \mathrm{~g}$ of the described palladium catalyst (Pd content: $111.15 \mathrm{mg} \mathrm{kg}^{-1}$ as defined by ICP-MS).

Promising results were recorded in terms of ByD conversion $(C>90.5 \%)$ and selectivity towards $(Z)-\mathrm{BeD}(S>95 \%)$ over 15 min of MW irradiation $\left(65^{\circ} \mathrm{C}\right)$ even using more concentrated ByD solution (5\%) with no detectable signs of catalyst deactivation over $4 \mathrm{~h}$ reaction time. These results are completely comparable with those obtained on a small scale ByD continuous flow MW semi-hydrogenation, and this confirms the effectiveness of the adopted strategy.

The intrinsic benefit of the described MW continuous flow system over conventional flow processes ${ }^{5}$ was proved potentially competitive on the large scale.

The use of MW gives the possibility to carry out the reaction without any selectivity promoter, which would make the process less green from an environmental point of view. Moreover, significant advantage in terms of both productivity per unit of active metal and alkyne volume to be reacted, is found when the reaction is promoted by MW.

Representative catalyst data for ByD MW semihydrogenation (0.05-5 w/v\% ByD ethanol solution) performed in Flow SYNTH device were summarized in Table 1 in terms of mass productivity $\left(\mathrm{mol} \mathrm{gM}^{-1} \mathrm{~h}^{-1}\right)$ and space time yield (STY). ${ }^{52}$

The highest catalyst productivity (around $70 \mathrm{~mol} \mathrm{gM}^{-1} \mathrm{~h}^{-1}$ ) on a more concentrated ByD scale for its continuous semihydrogenation could be justified in terms of both high

Table 1 Continuous flow scalability tests on ByD microwave semi-hydrogenation

\begin{tabular}{|c|c|c|c|c|c|c|c|}
\hline Entry $^{a}$ & Catalyst $^{b}(\mathrm{~g})$ & $\mathrm{ByD}^{c}(\mathrm{w} / \mathrm{v} \%)$ & Conv. (\%) & Sel. (\%) & Yield (\%) & Prod. $^{d}\left(\operatorname{mol~gM}{ }^{-1} \mathrm{~h}^{-1}\right)$ & $\operatorname{STY}^{e}\left(\mathrm{~kg} \mathrm{~L}{ }^{-1} \mathrm{~h}^{-1}\right)$ \\
\hline 1 & 6 & 0.05 & 90.5 & 95.2 & 90.5 & 7.1 & $0.7 \times 10^{-3}$ \\
\hline 2 & 12 & 0.5 & 90.5 & 94.8 & 90.4 & 35 & $0.7 \times 10^{-2}$ \\
\hline 3 & 36 & 2.5 & 90.8 & 95.3 & 90.7 & 60 & $0.4 \times 10^{-1}$ \\
\hline 4 & 60 & 5 & 90.3 & 95.0 & 90.2 & 71 & $0.7 \times 10^{-1}$ \\
\hline
\end{tabular}

${ }^{a}$ Reaction condition: ByD flow rate $=10 \mathrm{~mL} \mathrm{~min}^{-1} ; \mathrm{H}_{2}$ flow rate $=7.5 \mathrm{~mL} \mathrm{~min}{ }^{-1}$; residence time $=60 \mathrm{~s}$; temperature $65^{\circ} \mathrm{C} .{ }^{b}$ Activated Pd catalyst (Pd content $=111.15 \mathrm{mg} \mathrm{kg}^{-1}$ as defined by ICP-MS). ${ }^{c}$ ByD ethanol solution. ${ }^{d}$ Catalyst mass productivity (Prod.). ${ }^{e}$ Space time yield (STY). 
accessibility of Pd sites and high permeability of the embedded activated catalyst $(60 \mathrm{~g})$ inside the reactor chamber $(20 \mathrm{~mL}$ max volume) due to the MW improved heat and mass transfer effects in bigger catalyst scale. ${ }^{53}$

In addition, the amount of $\mathrm{H}_{2}$ for a residence time of $60 \mathrm{~s}$ under optimized conditions was calculated ( $28 \mathrm{mg}$ of hydrogen) and corresponds to a very high alkyne: hydrogen ratio. However, this value was noticeable improved when scaling up the process. An alkyne : hydrogen ratio equal to 1.75 was obtained. This value falls in the appropriate range (1-30) for carrying out the reaction, according to the very recent review by Barbaro et al. $^{5}$

Therefore the MW-assisted flow system here described could represent a favourable alternative to conventional partialhydrogenation performed under continuous-flow.

\section{Conclusions}

The crucial role that enabling technologies, such as US and MW, play in the design of more efficient and safer protocols for alkyne selective semi-hydrogenations in flow mode, has been fully demonstrated. High selectivity was achieved without the addition of promoters. Furthermore, a novel, yet simple, sonochemical synthesis of highly dispersed and stable Pd nanoparticles loaded on non-functionalised alumina spheres has been reported. These nanoparticles have uniform size and expose peculiar crystalline facets. Despite the physical stresses caused by dielectric heating and liquid and gas flow under pressure, Pd nanoparticle size remained almost constant. In the way of a further scaling up, preliminary tests were carried out to increase the amount of substrate in the reacting mixture up to $5 \%$ with promising results in term of mass productivity. Flow microwave technology enables reactions to be scaled-up from gram to kilogram scales, which should easily pave the way for industrial pilot reactors.

\section{Conflicts of interest}

There are no conflicts to declare.

\section{Acknowledgements}

The authors gratefully acknowledge funding from the EU project MAPSYN (grant agreement No. CP-IP 309376, seventh Framework Program). M. M. thanks the University of Turin for the funding "Ricerca Locale 2016-17". The authors gratefully acknowledge Agnese Giacomino for ICP-MS analysis.

\section{Notes and references}

1 K. Karunananda and N. P. Mankad, J. Am. Chem. Soc., 2015, 137, 14598.

2 H. Lindlar, Helv. Chim. Acta, 1952, 35, 446.

3 (a) A. Jung, A. Jess, T. Schubert and W. Schütz, Appl. Catal., A, 2009, 362, 95; (b) K. R. Campos, D. Cai, M. Journet, J. J. Kowal, R. D. Larsen and P. J. Reider, J. Org. Chem., 2001, 66, 3634-3635.
4 (a) M. Zhao, Chem.-Asian J., 2016, 11, 461; (b) J. A. Delgado, O. Benkirane, C. Claver, D. Curulla-Ferré and C. Godard, Dalton Trans., 2017, 46, 12381; (c) D. Yin, C. Li, H. Ren, O. Shekhah, J. Liu and C. Liang, $R S C A d v ., 2017$, 7, 1626; (d) H.-F. Li, Q.-S. Zhang, Z.-B. Pang, M. Tian, P. Gao and L.-L. Wang, Chin. Chem. Lett., 2016, 27, 1500; (e) S. Yang, C. Cao, L. Peng, J. Zhang, B. Hanc and W. Song, Chem. Commun., 2016, 52, 3627; (f) J. Yang, J.-J. Ma, D.-M. Zhang, T. Xue and Y.-J. Guan, Chin. Chem. Lett., 2016, 27, 1679.

5 C. Moreno-Marrodan, F. Liguori and P. Barbaro, Beilstein J. Org. Chem., 2017, 13, 734.

6 (a) S. G. Newman and K. F. Jensen, Green Chem., 2013, 15, 1456-1472; (b) M. Baumann and I. R. Baxendale, J. Org. Chem., 2015, 11, 1194-1219.

7 (a) C. Lucarelli and A. Vaccari, Green Chem., 2011, 13, 19411949; (b) I. Andrews, P. Dunn, J. Hayler, B. Hinkley, D. Hughes, B. Kaptein, K. Lorenz, S. Mathew, T. Rammeloo, L. Wang, A. Wells and T. D. White, Org. Process Res. Dev., 2011, 15, 22-30.

8 (a) R. Ricciardi, J. Huskens and W. Verboom, ChemSusChem, 2015, 8, 2586; (b) R. M. Myers, D. E. Fitzpatrick, R. M. Turnere and S. V. Ley, Chem.-Eur. J., 2014, 20, 12348.

9 (a) R. A. Sheldon, I. W. C. E. Arends and U. Hanefeld, Green Chemistry and Catalysis, Wiley-VCH, Weinheim, 2007; (b) I. R. J. Baxendale, J. Chem. Technol. Biotechnol., 2013, 88, 519. 10 (a) E. Joannet, C. Horny, L. Kiwi-Minsker and A. Renken, Chem. Eng. Sci., 2002, 57, 3453; (b) J. Nadgeri, M. Telkar and C. Rode, Catal. Commun., 2008, 9, 441.

11 Z. Wu, L. Rotolo, E. Calcio Gaudino, J. Medlock, W. Bonrath and G. Cravotto, Chem. Eng. Process., 2016, 110, 220.

12 N. Semagina, E. Joannet, S. Parra, E. Sulman, A. Renken and L. Kiwi-Minsker, Appl. Catal., A, 2005, 280, 141.

13 (a) C. Jiménez-González, P. Poechlauer, Q. B. Broxterman, B.-S. Yang, D. am Ende, J. Baird, C. Bertsch, R. E. Hannah, P. Dell'Orco, H. Noorman, S. Yee, R. Reintjens, A. Wells, V. Massonneau and J. Manley, Org. Process Res. Dev., 2011, 15, 900; (b) N. G. Anderson, Org. Process Res. Dev., 2012, 16, 852.

14 (a) D. Albani, G. Vilé, M. A. Beltran Toro, R. Kaufmann, S. Mitchell and J. Perez-Ramirez, React. Chem. Eng., 2016, 1, 454; (b) Y. Elias, P. Rudolf von Rohr, W. Bonrath, J. Medlock and A. Buss, Chem. Eng. Process., 2015, 95, 175; (c) S. Vernuccio, R. Goy, P. Rudolf von Rohr, J. Medlock and W. Bonrath, React. Chem. Eng., 2016, 1, 445; (d) F. Liguori and P. Barbaro, J. Catal., 2014, 311, 212; (e) R. P. Fishwick, R. Natividad, R. Kulkarni, P. A. McGuire, J. Wood, J. M. Winterbottom and E. H. Stitt, Catal. Today, 2007, 128, 108; (f) J. M. Winterbottom, H. Marwan, J. Viladevall, S. Sharma and S. Raymahasay, Stud. Surf. Sci. Catal., 1997, 108, 59.

15 C.-H. Pélisson, T. Nakanishi, Y. Zhu, K. Morisato, T. Kamei, A. Maeno, H. Kaji, S. Muroyama, M. Tafu, K. Kanamori, T. Shimada and K. Nakanishi, ACS Appl. Mater. Interfaces, 2017, 9, 406.

16 G. C. Bond, Metal-Catalysed Reactions of Hydrocarbons, Springer, New York, 2005. 
17 A. Sachsen, N. Linares, P. Barbaro and F. Fajula, Dalton Trans., 2013, 42, 1378.

18 (a) S. K. Ajmera, C. Delattre, M. A. Schmidt and K. F. Jensen, Stud. Surf. Sci. Catal., 2003, 145, 97; (b) C. D. Baertsch, M. A. Schmidt and K. F. Jensen, Chem. Commun., 2004, 22, 2610.

19 (a) K. Haas-Santo, M. Fichtner and K. Schubert, Appl. Catal., A, 2001, 220, 79; (b) V. Meille, Appl. Catal., A, 2006, 315, 1; (c) A. N. Tsoligkas, M. J. H. Simmons, J. Wood and C. G. Frost, Catal. Today, 2007, 128, 36.

20 L. B. Okhlopkova, M. A. Kerzhentsev and Z. R. Ismagilov, Kinet. Catal., 2016, 57, 497.

21 G. García Colli, J. A. Alves, O. M. Martínez and G. F. Barreto, Chem. Eng. Process., 2016, 105, 38.

22 T. H. Rehma, C. Berguerand, S. Ek, R. Zapf, P. Löb, L. Nikoshvili and L. Kiwi-Minsker, Chem. Eng. J., 2016, 293, 345.

23 (a) V. Hessel, G. Cravotto, P. Fitzpatrick, B. S. Patil, J. Lang and W. Bonrath, Chem. Eng. Process., 2013, 71, 19; (b) M. D. Bowman, J. R. Schmink, C. M. McGowan, C. M. Kormos and N. E. Leadbeater, Org. Process Res. Dev., 2008, 12, 1078.

24 C. Schmoeger, T. Gallert, A. Stolle, B. Ondruschka and W. Bonrath, Chem. Eng. Technol., 2011, 34, 445.

25 B. K. Banik, K. J. Barakat, D. R. Wagle, M. S. Manhas and A. K. Bose, J. Org. Chem., 1999, 64, 5746.

26 G. S. Vanier, Synlett, 2007, 18, 131.

27 E. Heller, W. Lautenschlaeger and U. Holzgrabe, Tetrahedron Lett., 2005, 46, 1247.

28 Z. Wu, E. Borretto, J. Medlock, W. Bonrath and G. Cravotto, ChemCatChem, 2014, 6, 2762.

29 C. Cau, Y. Guari, T. Chave, J. Larionova, P. Pochon and S. I. Nikitenko, J. Phys. Chem. C, 2013, 117, 22827.

30 S. Bedrane, C. Descorme and D. Duprez, J. Mater. Chem., 2002, 12, 1563.

31 G. Cravotto, W. Bonrath, J. Medlock, E. Borretto and Z. Wu, Process for preparation of Pd-on-boehmite catalytic systems for selective hydrogenation of triple bonds, PCT Int. Appl., WO 2015044411 A1 20150402, 2015.

32 G. Cravotto, W. Bonrath, J. Medlock, E. Borretto and Z. Wu, Process for preparation of Pd-on-boehmite catalytic systems for selective hydrogenation of triple bonds, PCT Int. Appl., WO 2015044411 A1 20150402, 2015.

33 Z. Wu, L. Rotolo, E. Calcio Gaudino, J. Medlock, W. Bonrath and G. Cravotto, Chem. Eng. Process., 2016, 110, 220.

34 (a) Z. Wu, N. Cherkasov, G. Cravotto, E. Borretto, A. O. Ibhadon, J. Medlock and W. Bonrath, ChemCatChem, 2015, 7, 952; (b) Z. Wu, G. Cravotto, E. Calcio Gaudino,
J. Medlock and W. Bonrath, Ultrason. Sonochem., 2017, 35, 664.

35 W. Bonrath, M. Eggersdorfer and T. Netscher, Catal. Today, 2007, 121, 45.

36 N. D. Havis, D. R. Walters, S. A. Foster, W. P. Martin, F. M. Cook and D. J. Robins, Pestic. Sci., 1994, 41, 61.

37 (a) M. Telkar, C. Rode, V. Rane, R. Jaganathan and R. Chaudhari, Appl. Catal., A, 2001, 216, 13; (b) N. Semagina, E. Joannet, S. Parra, E. Sulman, A. Renken and L. Kiwi-Minsker, Appl. Catal., A, 2005, 280, 141.

38 Z. Wu, E. Calcio Gaudino, M. Manzoli, K. Martina, M. Drobot, U. Krtschilc and G. Cravotto, Catal. Sci. Technol., 2017, 7, 4780.

39 (a) C. O. Kappe, Angew. Chem., Int. Ed., 2004, 43, 6250; (b) C. O. Kappe, Angew. Chem., 2004, 116, 6408.

40 M. Crespo-Quesada, M. Grasemann, N. Semagina, A. Renken and L. Kiwi-Minsker, Catal. Today, 2009, 147, 247.

41 S. Horikoshi, M. Kamata, T. Mitani and N. Serpone, Ind. Eng. Chem. Res., 2014, 53, 14941.

42 G. Cravotto and P. Cintas, Chem. Soc. Rev., 2006, 35, 180.

43 (a) K. S. Suslick, Science, 1990, 247, 1439; (b) W. B. McNamara, Y. T. Didenko and K. S. Suslick, Nature, 1999, 401, 772.

44 L.-X. Zuo, L.-P. Jiang and J.-J. Zhu, Ultrason. Sonochem., 2017, $35,681$.

45 H. Jeon and Y.-M. Chung, Appl. Catal., B, 2017, 210, 212.

46 (a) J. Silvestre-Albero, G. Rupprechter and H. J. Freund, J. Catal., 2005, 35, 52; (b) J. Silvestre-Albero, G. Rupprechter and H.-J. Freund, J. Catal., 2006, 240, 58; (c) V. Climent and J. M. Feliu, J. Solid State Electrochem., 2011, 15, 1297; (d) J. V. Perales-Rondón, J. Solla-Gullón, E. Herrero and C. M. Sánchez-Sánchez, Appl. Catal., B, 2017, 201, 48.

47 M. Crespo-Quesada, A. Yarulin, M. Jin, Y. Xia and L. KiwiMinsker, J. Am. Chem. Soc., 2011, 133, 12787.

48 A. Presianni, M. Crespo-Quesada, R. Cortese, F. Ferrant, L. Kiwi-Minsker and D. Duca, J. Phys. Chem. C, 2014, 118, 3119.

49 A. Yarulin, R. M. Crespo-Quesada, E. V. Egorova and L. KiwiMinsker, Kinet. Catal., 2012, 53, 253.

50 (a) A. N. R. Bos and K. R. Westerterp, Chem. Eng. Process., 1993, 32, 1; (b) A. Borodzinski and A. Golebiowski, Langmuir, 1997, 13, 883.

51 A. Moghtada, A. Shahrouzianfar and R. Ashiri, Adv. Powder Technol., 2017, 228, 1109.

52 D. Pletcher and F. Walsh, Industrial Electrochemistry, Springer, London, 1990, p. 83.

53 Microwave Chemistry, ed. G. Cravotto and D. Carnaroglio, De Gruyter Graduate, Berlin, 2017. 